\title{
NOTES ON CONVENTIONS
}

1. Wherever possible, women are identified by name, rather than as a man's daughter, wife, or mother. The wife of Ssu-ma Kuang, for instance, is referred to as Miss Chang (1023-1082). Chang was the name of her natal family, a name she retained her whole life. If her given name was recorded, it is also given in Chinese style after the family name, as in Miss Shen Te-jou (1119-1179). In most cases, given names are not known. In ordinary social life, a married woman was called by her original family name with the polite term shih attached. Shih is translated here as Miss because it was attached to the woman's natal family name, not her husband's family name. By itself, it did not indicate marital status. Although shih could also be attached to a man's family name, men were much more commonly referred to by their family names and a personal name. In the uncommon case in which a woman is only known as the wife of a named man, she is referred to by his family name prefaced by Mrs. Referring to men by their family and given names alone (i.e., not as Mr. Ssu-ma Kuang) and women by names prefaced by Miss or Mrs. may violate contemporary American rules on the avoidance of sexist language, but it was adopted here as the least of several evils. It captures Chinese usage quite accurately; in the case of men, it is less cumbersome than using Mr. as well; yet it still alerts readers to the sex of everyone mentioned.

2. Other than the six authors discussed in the Introduction (Hung Mai, Ssu-ma Kuang, Yüan Ts'ai, Ch'eng I, Chu Hsi, and Miss Li Ch'ing-chao), all men and women have their dates indicated if known, even when their dates seem to have nothing to do with the points being made. This is intended to underline that they were specific people, not generic stereotypes, and also to keep separate the many women called Miss Chang or 
Miss Wu. Providing dates also allows concerned readers to consider issues of historical change, such as the gradual increase in the influence of Neo-Confucianism.

3. Ages are given by Chinese reckoning in sui. A phrase such as "he died at forty" means he died at forty sui. On the average, sui ages will be a year older than Western ages. By sui reckoning, a person is one from the date of birth until the first New Year's Day, when he or she turns two. Thus, a girl who marries at eighteen sui could be anywhere from a day over sixteen by our reckoning (if she was born on the thirty-first day of the twelfth month of the year 1000 and married on the first of the first month of the year 1017) to a day under eighteen (if she was born on the first day of the first month of 1000 and married on the thirty-first of the twelfth month of 1017).

4. For convenience, places are identified according to modern province names rather than Sung circuits. See the following map for the borders of Northern and Southern Sung superimposed on the modern provinces of China proper.

5. All translations given here are my own. When a translation into English is available, it is cited after the primary source citation as a convenience to readers who would like to check the full passage.

6. The only abbreviation used in the body of this book is c.s. with a date. This refers to the year a man passed the chin-shih examination, and is given when the man's birth and death dates are not known. 


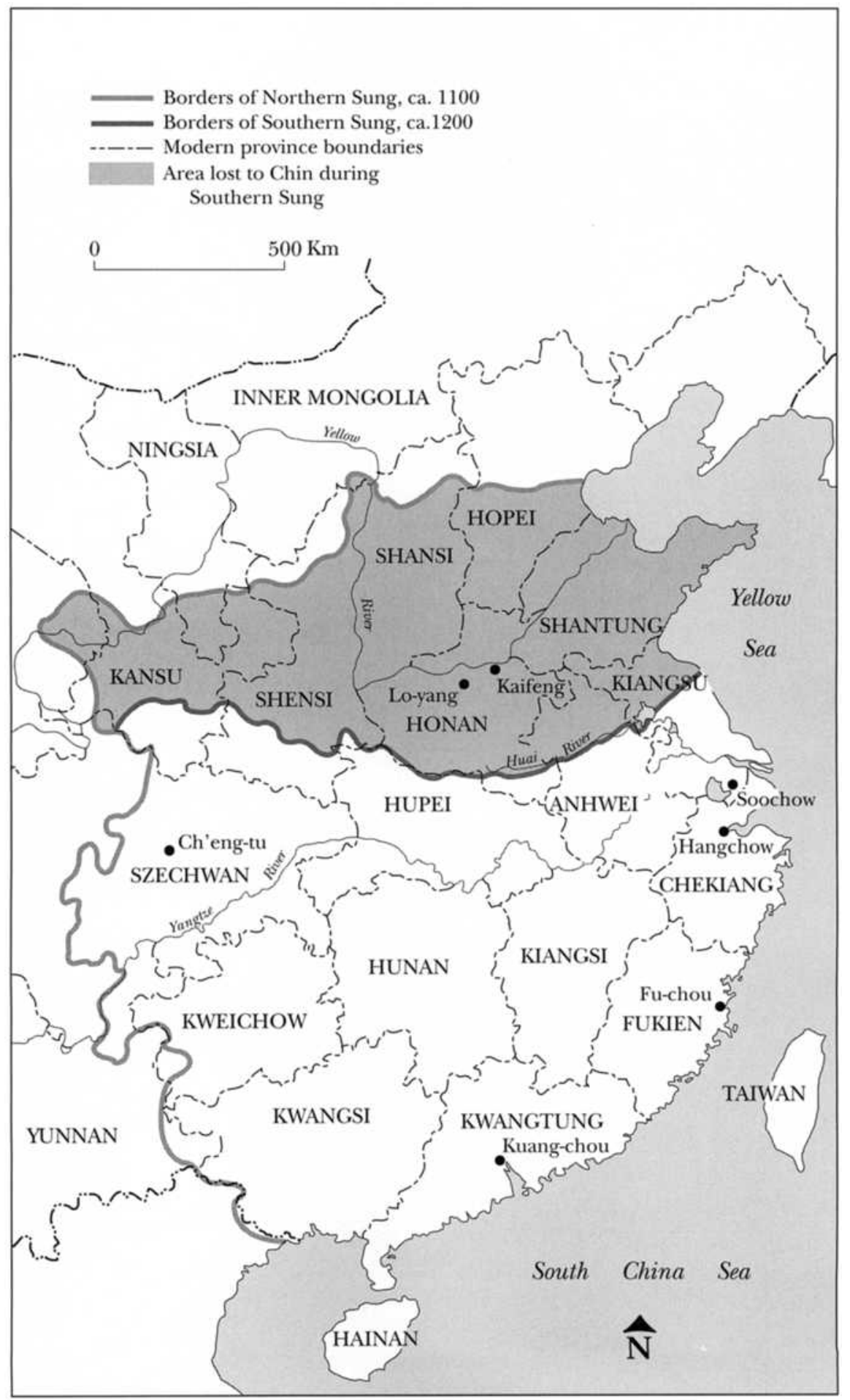

The Borders of Sung China (960-1279) (set against modern province boundaries) 
This page intentionally left blank 